Educación Física y Ciencia, vol. 23, n³, e184, julio-septiembre 2021. ISSN 2314-2561

Universidad Nacional de La Plata.

Facultad de Humanidades y Ciencias de la Educación.

Departamento de Educación Física

\title{
O basquetebol em números: análise de indicadores de jogo do NBB 2018-2019
}

\author{
Basketball in numbers: analysis of game indicators for the NBB 2018-2019 season \\ Baloncesto en números: análisis de los indicadores de juego de la temporada NBB 2018-2019
}

\author{
Felipe Canan \\ Universidade do Estado do Amazonas, Brasil \\ felipe.canan@gmail.com \\ iD https://orcid.org/0000-0002-9450-778X
}

\author{
João Paulo Melleiro Malagutti \\ Universidade Estadual de Maringá, Brasil \\ joaopaulomalagutti89@hotmail.com \\ (iD https://orcid.org/0000-0002-9906-9758
}

\author{
Edson Hirata \\ Universidade Tecnológica Federal do Paraná - Campus \\ Campo Mourão, Brasil \\ chinahirata@gmail.com \\ (iD https://orcid.org/0000-0001-6084-5724
}

\begin{abstract}
Resumo:
Objetivou-se identificar os indicadores de jogo mais importantes para vitória em uma partida e para a definição da colocação final na fase de classificação da temporada 2018-2019 do Novo Basquete Brasil. A pesquisa é quantitativa-descritiva e analisou 43 indicadores diretos (box score) e indiretos de jogo (estatísticas avançadas e four factors), além da pontuação parcial das 179 partidas disponibilizadas no site da LNB. Computou-se valores totais e médias e quantidades e percentuais de vezes em que o vencedor ou perdedor de cada partida foi superior em cada indicador e em que o primeiro e o último colocado da fase de classificação da competição foram superiores em cada indicador. Identificou-se que indicadores relacionados à quantidade e percentual de acerto de arremesso em geral são preponderantes para vitória em cada partida e para terminar em primeiro lugar na fase de classificação. Rebotes são mais importantes para vitória em cada partida do que para primeira colocação na fase de classificação. Em termos gerais, equipes vitoriosas têm mais cuidado com a bola e melhor seleção de arremessos.
\end{abstract}

Palavras-chave: Esporte, Basquetebol, NBB.

\begin{abstract}
:
The objective of this work was to identify the most important game indicators for victory in a match and to define the final placement in the classification phase of the 2018-2019 season of the New Basketball Brazil [Novo Basquete Brasil, in Portuguese]. The research is quantitative-descriptive and analyzes 43 direct (box score) and indirect game indicators (advanced statistics and four factors), in addition to the partial score of the 179 games available on the National Basketball League [Liga Nacional de Basquete, in Portuguese] website. Total and average values,quantities and percentages of times were calculated when the winner or loser of each match was superior in each indicator and in which the first and last place of the competition classification phase were superior as well in each indicator. It was identified that indicators related to the quantity and percentage of correct pitches in general are preponderant for victory in each match and to end up first in the classification phase. Rebounds are more important for victory in each match than for first place in qualifying. In general terms, winning teams are more careful with the ball and have better selection of shots.
\end{abstract}

KeYwords: Sport, Basketball, NBB. 


\section{Resumen:}

El objetivo fue identificar los indicadores de juego más importantes para ganar un partido y definir el lugar final en la fase de clasificación de la temporada 2018-2019 de Novo Basquete Brasil. La investigación es cuantitativo-descriptiva y analizó 43 indicadores de juego directos (box score) e indirectos (estadísticas avanzadas y cuatro factores), además de la puntuación parcial de los 179 partidos disponibles en la web de la LNB. Se computaron valores totales y promedios y cantidades y porcentajes de tiempos en los que el ganador o perdedor de cada partido fue superior en cada indicador y en los que el primer y último lugar en la fase de clasificación de la competencia fueron superiores en cada indicador. Se identificó que los indicadores relacionados con la cantidad y porcentaje de aciertos en general son preponderantes para la victoria en cada partido y para terminar en primer lugar en la fase de clasificación. Los rebotes son más importantes para ganar cada partido que para el primer lugar en la ronda de clasificación. En términos generales, los equipos ganadores son más cuidadosos con el balón y tienen mejor selección de tiros.

Palabras Clave: Deporte, Basquetbol, NBB.

\section{INTRODUÇÃO}

O basquetebol, como os demais jogos esportivos coletivos, é uma modalidade esportiva de caráter complexo, caracterizado por seu aspecto situacional-contextual e consequente imprevisibilidade dos acontecimentos e ações dos jogadores (De Rose Junior, 2011). Por essa razão, não pode ser ilustrado por apenas um de seus componentes isoladamente, seja tático, técnico, físico e psicológico.

A análise realizada a partir de indicadores de jogo (box scores), nesse sentido, visa, senão fornecer detalhes sobre o jogo em sua complexidade, ao menos oferecer um retrato numérico de ações realizadas por jogadores e equipes e relações entre essas ações e a vitória ou a derrota em cada partida e na classificação final de uma competição (De Rose Junior, Gaspar \& Assumpção, 2005; Carvalho, Janeira \& Brandão, 2006; Dias Neto, 2007; Csataljay et al., 2009; Tavares, 2011; Almas, 2015; Canan, Mendes \& Silva, 2015; Prochnow et al., 2017).

Ao mesmo tempo, a análise de indicadores de jogo, embora menos completa que o scout, que busca verificar indicadores qualitativos, como tomadas de decisão, além das ações em si (De Rose Junior, Tavares, Gitti, 2004; De Rose Junior, Gaspar, Assumpção, 2005; Canan, Mendes, Silva, 2015; Meneses, Gois Junior, Almeida, 2016), tem evoluído a partir de fórmulas matemáticas, chamadas estatísticas avançadas, que deixam de simplesmente quantificar ações realizadas pelos jogadores/equipes, para também relacioná-las e, a partir delas, oferecer retratos possíveis de importantes padrões de jogo e desempenho dos jogadores (Lewis, 2003; Kubatko et al., 2007; Malarranha, 2011; Larkin \& O'connor, 2017; Den Hartigh et. al., 2018; Enge, 2018; Araújo, 2020).

Ou seja, a análise de indicadores de jogo baseia-se em números, mas busca, a partir deles, identificar também comportamentos e padrões qualitativos, indo além da mera quantificação e, principalmente, de uma simples análise subjetiva da partida. Com isso, a análise de indicadores de jogo pode ajudar managers e treinadores na formação do elenco e treinamento da equipe (Lewis, 2003; Sampaio, Lago \& Drinkwater, 2010; Malarranha, 2011; Carneiro, Souza, Costa, 2015; Larkin \& O'connor, 2017; Den Hartigh et. al., 2018).

Considerando, assim, a análise de indicadores de jogo como um importante instrumento de avaliação de desempenho em partidas e competições de basquetebol, esta pesquisa objetivou, em termos gerais, identificar os indicadores de jogo mais importantes para vitória em uma partida e para a definição da colocação final na fase de classificação do Novo Basquete Brasil (NBB), principal competição nacional de basquetebol para homens.

\section{METODOLOGIA}

A pesquisa é quantitativa com objetivos descritivos, tendo como objeto os indicadores estatísticos da fase de classificação da temporada 2018-2019 do NBB, última completa da competição até setembro de 2020, 
período da coleta de dados ${ }^{1}$. Todos os indicadores diretos de jogo, ou seja, aqueles que dizem respeito ao que o jogador efetivamente faz na partida foram coletados junto ao site eletrônico da Liga Nacional de Basquete (LNB), entidade responsável pela organização do Novo Basquete Brasil.

A fase de classificação da temporada 2018-2019 contou com 14 equipes e um total de 182 partidas. Entretanto, os dados estatísticos de três partidas não constam no site (página com problemas técnicos), de forma que a amostra foi composta pelas demais 179 partidas. Cada equipe realizou um total de 26 partidas, mas uma das partidas da equipe última colocada na fase de classificação é uma daquelas cuja página eletrônica apresenta problemas. Dessa forma, as análises sobre a equipe primeira colocada na fase de classificação levaram em conta suas 26 partidas e as análises sobre a equipe última colocada na fase de classificação levaram em conta 25 das suas 26 partidas.

Além dos indicadores diretos de jogo, foram analisados: os indicadores indiretos, obtidos a partir de fórmulas matemáticas que se utilizam dos indicadores diretos; os chamados quatro fatores ou four factors, que são quatro indicadores indiretos considerados pela literatura (Kubatko et al., 2007; Malarranha, 201 1; Enge, 2018; Pivotanalysis, 2019; Nbastuffer, 2020) como preponderantes para que uma equipe vença uma partida; e os resultados parciais das partidas (Ferreira, 2006; Ferreira \& Barreto, 2008), ou seja, de cada período (P) individualmente e resultado da partida ao final do segundo e do terceiro períodos. Não foi computada a pontuação de períodos extras, quando aconteceram. Os indicadores e as respectivas fórmulas matemáticas são apresentados no quadro 01 (Kubatko et al., 2007; Malarranha, 2011; Canan, Mendes \& Silva, 2015; Enge, 2018; Pivotanalysis, 2019; Nbastuffer, 2020). A explicação sobre eles é realizada na própria apresentação dos resultados. 
QUADRO 01

Indicadores de jogo analisados na pesquisa

\begin{tabular}{|c|c|c|}
\hline Indicadores diretos & Indicadores indiretos & $\begin{array}{l}\text { Quatro } \\
\text { fatores }\end{array}$ \\
\hline Arremessos de 3 por & \multirow{2}{*}{$\begin{array}{c}\text { Percentual de acerto de } \\
\text { arremessos de } 3 \text { pontos }(\% 3 \mathrm{P})= \\
(3 \mathrm{PC} * 100) / 3 \mathrm{PT}\end{array}$} & \multirow{8}{*}{$\begin{array}{c}\text { Porcentagem } \\
\text { efetiva de } \\
\text { arremessos } \\
\text { de quadra } \\
(\% \mathrm{EAQ})= \\
(\mathrm{AQC}+0,5 \\
\text { *3PC) } / \\
\mathrm{AQT}\end{array}$} \\
\hline Arremesso de 3 pontos convertidos (3PC) & & \\
\hline Arremessos de 3 pontos & \multirow{2}{*}{$\begin{array}{c}\text { Percentual de acerto de } \\
\text { arremessos de } 2 \text { pontos }(\% 2 \mathrm{P})= \\
(2 \mathrm{PC} * 100) / 2 \mathrm{PT}\end{array}$} & \\
\hline Arremessos de 2 pontos tentados (2PT) & & \\
\hline Arremesso de 2 ponto & \multirow{2}{*}{$\begin{array}{c}\text { Percentual de acerto de lances } \\
\text { livres }(\% L L)=(L L C * 100) / \\
\text { LLT }\end{array}$} & \\
\hline Arremessos de 2 pontos errados (2PE) & & \\
\hline Lance & \multirow{2}{*}{$\begin{array}{c}\text { Eficiência }(\mathrm{EF})=(\mathrm{PF}+\mathrm{RT}+\mathrm{AS} \\
+\mathrm{BR}+\mathrm{TO}+\mathrm{FR})-(3 \mathrm{PE}+2 \mathrm{PE}+ \\
\mathrm{LLE}+\mathrm{FC}+\mathrm{ER})\end{array}$} & \\
\hline Lances livres convertidos (LLC) & & \\
\hline Lance & \multirow{2}{*}{$\begin{array}{c}\text { Assistências por erros (AS/ER) }= \\
\text { AS } / E R\end{array}$} & \multirow{7}{*}{$\begin{array}{c}\text { Porcentagem } \\
\text { de rebotes } \\
\text { ofensivos } \\
(\% \mathrm{RO})= \\
\mathrm{RB} /(\mathrm{RO}+ \\
\mathrm{RD} \\
\text { adversário) }\end{array}$} \\
\hline Total arremessos de quadra tentados (AQT) & & \\
\hline $\begin{array}{l}\text { Total arremessos de quadra convertidos } \\
\qquad(\mathrm{AQC})\end{array}$ & \multirow{2}{*}{$\begin{array}{l}\text { Bolas recuperadas por erros } \\
\qquad(\mathrm{BRER})=\mathrm{BR} / \mathrm{ER}\end{array}$} & \\
\hline Total arremessos & & \\
\hline Total arremess & \multirow{2}{*}{$\begin{array}{l}\text { Bolas recuperados por faltas } \\
\text { cometidas }(\mathrm{BR} F \mathrm{FC})=\mathrm{BR} / \mathrm{FC}\end{array}$} & \\
\hline Total pontos de quadra tentados (PQT) & & \\
\hline Total pontos de quadra feitos (PQF) & \multirow{2}{*}{$\begin{array}{c}\text { Tocos por erros }(\mathrm{TO} / \mathrm{ER})=\mathrm{TO} / \\
\mathrm{ER}\end{array}$} & \\
\hline Total pontos tentados (PT) & & Razão ou \\
\hline Total pontos feitos (PF) & \multirow{2}{*}{$\begin{array}{l}\text { Tocos por faltas cometidas } \\
(\mathrm{TO} / \mathrm{FC})=\mathrm{TO} / \mathrm{FC}\end{array}$} & proporção \\
\hline Rebotes defensivos (RD) & & de lances \\
\hline Rebotes ofensivos (RO) & \multirow{2}{*}{$\begin{array}{c}\text { Porcentagem de rebotes } \\
\text { defensivos }(\% R D)=R D /(R D+ \\
R O \text { adversário })\end{array}$} & livres \\
\hline Rebotes totais (RT) & & $\begin{array}{c}\text { tentados } \\
(\text { RALLT) }=\end{array}$ \\
\hline Assistências (AS) & \multirow{2}{*}{$\begin{array}{c}\text { Posses de bola (PB) }=\text { AQT - RO } \\
+ \text { ER }+0,4^{*} \mathrm{LLT}\end{array}$} & $\mathrm{LLT} / \mathrm{AQT}$ \\
\hline Bolas recuperadas (BR) & & Razão ou \\
\hline Tocos (TO) & \multirow{2}{*}{$\begin{array}{c}\text { Razão ou proporção (rate) } \\
\text { ofensiva }(\text { RAO) }=[\text { PF } /(\mathrm{PB} * \\
100)]^{*} 100\end{array}$} & proporção \\
\hline Faltas cometidas (FC) & & $\begin{array}{c}\text { de erros } \\
(\mathrm{RAER})=\end{array}$ \\
\hline Faltas recebidas (FR) & \multirow{2}{*}{$\begin{array}{c}\text { Razão ou proporção (rate) } \\
\text { defensiva }(\mathrm{RAD})=[\mathrm{PF} \text { adversário } \\
/(\mathrm{PB} \text { adversário } * 100)]^{*} 100\end{array}$} & \\
\hline Erros (ER) & & $\begin{array}{c}+0,44^{*} \\
\mathrm{LLT}+\mathrm{ER})\end{array}$ \\
\hline
\end{tabular}

Fonte: os autores.

As categorias de análise, dessa forma, que serviram como roteiro para apresentação e discussão dos resultados, foram, nessa ordem: resultados parciais da partida; indicadores diretos; indicadores indiretos; quatro fatores. Sobre cada uma, quatro análises diferentes foram realizadas: [1] diferença de totais e médias (para indicadores diretos) ou somente médias (para indicadores indiretos e quatro fatores) entre o vencedor e o perdedor de cada partida; [2] diferença de vezes (quantidade de partidas) em que o vencedor e o perdedor de cada partida venceram em cada indicador; [3] diferença de totais e médias (para indicadores diretos) ou somente médias (para indicadores indiretos e quatro fatores) entre o primeiro e o último colocado na fase de classificação da competição e seus respectivos adversários; [4] diferença de vezes (quantidade de partidas) em que o primeiro e o último colocado na fase de classificação da competição venceram seus respectivos adversários em cada indicador.

Os dados relativos aos totais e médias de cada equipe ajudam na identificação de padróes positivos e negativos para vitória ou derrota, mas eles podem ser influenciados por situações isoladas, ou seja, por um ou algumas partidas muito boas ou ruins feitas pela equipe. Por isso, foi realizada a análise conjunta dos dados relativos à quantidade e percentual de vezes em que a equipe venceu no indicador, em busca de identificar padrões estáveis. A análise estatística foi descritiva e percentual. A finalidade é que os resultados indiquem quais os indicadores de jogo mais importantes para uma equipe vencer uma partida e para vencer a fase de classificação do NBB. 


\section{RESULTADOS E DISCUSSÃO}

\section{Resultados parciais das partidas}

Os resultados parciais das partidas, segundo Ferreira (2006) e Ferreira e Barreto (2008), apresentam uma associação positiva com o resultado final da partida, mostrando-se, por isso, um indicador importante para ser levado em consideração por equipes e treinadores durante a preparação e as partidas.

TABELA 01

Total e média de pontos feitos pelo vencedor e perdedor de cada partida, e diferença entre eles:

$\begin{array}{cccc}\text { Período } & \text { Vencedor } & \text { Perdedor } & \text { Diferença } \\ \mathbf{1}^{\circ} \mathbf{P} & 3754(21) & 3276(18,3) & 478(2,7) \\ \mathbf{2}^{\circ} \mathbf{P} & 3678(20,5) & 3119(17,4) & 559(3,1) \\ \mathbf{3}^{\circ} \mathbf{P} & 3826(21,4) & 3349(18,7) & 477(2,7) \\ \mathbf{4}^{\circ} \mathbf{P} & 3931(22) & 3466(19,4) & 465(2,6) \\ \mathbf{1}^{\mathbf{0}} \mathbf{e} \mathbf{2}^{\circ} \mathbf{P} \text { somados } & 7432(41,5) & 6395(35,7) & 1037(5,8) \\ \mathbf{1}^{\circ}, \mathbf{2}^{\circ} \mathbf{e} \mathbf{3}^{\circ} \mathbf{P} & 11258 & & \\ \text { somados } & (62,9) & 9744(54,4) & 1514(8,5) \\ & & & \end{array}$

Fonte: dados da pesquisa.

É possível perceber que as equipes vencedoras e perdedoras de cada partida fazem o maior número de pontos no quarto período $\left(4^{\circ} \mathrm{P}\right)$ e menor no segundo período $\left(2^{\circ} \mathrm{P}\right)$. Em termos de diferença, o período que se apresenta mais importante para vitória na partida, se considerado individualmente, é o segundo $\left(2^{\circ} \mathrm{P}\right)$. Contudo, terminar o segundo período $\left(1^{\circ} \mathrm{e} 2^{\circ} \mathrm{P}\right.$ somados $)$ à frente e, principalmente, terminar o terceiro período $\left(1^{\circ}, 2^{\circ}\right.$ e $3^{\circ} \mathrm{P}$ somados $)$ à frente no placar mostra-se como um fator mais importante do que vencer qualquer período individualmente (ver Tabela 02).

Tabela 02: Frequência e percentual de vezes em que vencedor e perdedor de cada partida vence o período ou soma de períodos, e diferença entre eles:

TABELA 02

Frequência e percentual de vezes em que vencedor e perdedor de cada partida vence o período ou soma de períodos, e diferença entre eles:

\begin{tabular}{cccc} 
Período & Vencedor & Perdedor & Diferença \\
$\mathbf{1}^{\circ} \mathbf{P}$ & $112(62,6 \%)$ & $59(33 \%)$ & $53(29,6 \%)$ \\
$\mathbf{2}^{\circ} \mathbf{P}$ & $120(67 \%)$ & $56(31,3 \%)$ & $64(35,8 \%)$ \\
$\mathbf{3}^{\circ} \mathbf{P}$ & $114(63,7 \%)$ & $57(31,8 \%)$ & $57(31,8 \%)$ \\
$\mathbf{4}^{\circ} \mathbf{P}$ & $116(64,8 \%)$ & $57(31,8 \%)$ & $59(33 \%)$ \\
$\mathbf{1}^{\circ} \mathbf{e} \mathbf{2}^{\circ} \mathbf{P}$ somados & $140(78,2 \%)$ & $35(19,6 \%)$ & $105(58,7 \%)$ \\
$\mathbf{1}^{\circ}, \mathbf{2}^{\circ} \mathbf{e} \mathbf{3}^{\circ} \mathbf{P}$ & $149(83,2 \%)$ & $28(15,6 \%)$ & $121(67,6 \%)$ \\
somados & & & \\
\hline
\end{tabular}

Fonte: dados da pesquisa.

Como identificado na Tabela 02 , o segundo período $\left(2^{\circ} \mathrm{P}\right)$ mostra-se sumariamente importante, sendo o mais vencido pelo vencedor da partida, fato possivelmente explicado pela profundidade do elenco, vez 
que, em regra, os titulares da equipe têm maior tempo de quadra nos períodos inicial $\left(1^{\circ} \mathrm{P}\right)$ e final $\left(4^{\circ} \mathrm{P}\right)$ da partida. Ainda assim, como também em acordo com a Tabela 01, mais do que vencer qualquer período individualmente, é importante para equipe terminar o segundo ( $1^{\circ}$ e $2^{\circ} \mathrm{P}$ somados) e principalmente o terceiro período $\left(1^{\circ}, 2^{\circ}\right.$ e $3^{\circ} \mathrm{P}$ somados $)$ à frente no placar para que obtenha a vitória na partida. Canan, Mendes e Silva (2015), estudando o basquetebol de base brasileiro e Ferreira (2006) e Ferreira e Barreto (2008), estudando o basquetebol adulto português, encontraram resultados semelhantes a respeito da importância do segundo período $\left(2^{\circ} \mathrm{P}\right)$ e de terminar o terceiro período $\left(1^{\circ}, 2^{\circ}\right.$ e $3^{\circ} \mathrm{P}$ somados $)$ à frente no placar (ver Tabela 03).

\section{TABELA 03}

Total e média de pontos feitos pelo primeiro e último colocado na fase de classificação e respectivos adversários e diferença entre eles (o resultado negativo nas colunas de diferenças significa que o primeiro ou último colocado perdeu dos seus adversários naquele período).

\begin{tabular}{|c|c|c|c|c|c|c|}
\hline Período & $\begin{array}{l}\text { Primeiro } \\
\text { colocado }\end{array}$ & $\begin{array}{c}\text { Adversários } \\
\text { do primeiro } \\
\text { colocado }\end{array}$ & $\begin{array}{c}\text { Diferença } \\
\text { primeiro } \\
\text { colocado e } \\
\text { adversários }\end{array}$ & $\begin{array}{c}\text { Último } \\
\text { colocado }\end{array}$ & $\begin{array}{c}\text { Adversários } \\
\text { do último } \\
\text { colocado }\end{array}$ & $\begin{array}{c}\text { Diferença } \\
\text { último } \\
\text { colocado e } \\
\text { adversários }\end{array}$ \\
\hline $1^{\circ} \mathrm{P}$ & $603(23,2)$ & $486(18,7)$ & $117(4,5)$ & $506(20,2)$ & $497(19,9)$ & $9(0,4)$ \\
\hline $2^{\circ} \mathrm{P}$ & $529(20,3)$ & $465(17,9)$ & $64(2,5)$ & $427(17,1)$ & $539(21,6)$ & $-112(-4,5)$ \\
\hline $3^{\circ} \mathrm{P}$ & $593(22,8)$ & $490(18,8)$ & $103(4)$ & $442(17,7)$ & $527(21,1)$ & $-85(-3,4)$ \\
\hline $4^{\circ} \mathrm{P}$ & $533(20,5)$ & $545(21)$ & $-12(-0,5)$ & $534(21,4)$ & $532(21,3)$ & $2(0,1)$ \\
\hline $\begin{array}{l}1^{\circ} \text { e } 2^{\circ} \mathrm{P} \\
\text { somados }\end{array}$ & $1132(436)$ & $951(36,6)$ & $181(7)$ & $933(37,3)$ & $1036(41,4)$ & $-103(-4,1)$ \\
\hline $\begin{array}{c}1^{\circ}, 2^{\circ} \text { e } 3^{\circ} \mathrm{P} \\
\text { somados }\end{array}$ & $\begin{array}{c}1725 \\
(66,3)\end{array}$ & $1441(55,4)$ & $284(10,9)$ & $1375(55)$ & $1563(62,5)$ & $-188(-7,5)$ \\
\hline
\end{tabular}

Fonte: dados da pesquisa.

O principal período para ser primeiro colocado na fase de classificação foi o primeiro $\left(1^{\circ} \mathrm{P}\right)$. Em contrapartida, o quarto período $\left(4^{\circ} \mathrm{P}\right)$ mostrou-se o pior, sendo o único em que a equipe primeira colocada na fase de classificação perdeu de seus adversários, o que pode ser explicado pelo fato de chegar a ele com uma média de 10,9 pontos à frente no placar. Terminar o segundo $\left(1^{\circ} \mathrm{e} 2^{\circ} \mathrm{P}\right.$ somados $)$ e principalmente o terceiro períodos $\left(1^{\circ}, 2^{\circ}\right.$ e $3^{\circ} \mathrm{P}$ somados $)$ à frente mostrou-se como fator mais importante do que vencer qualquer um dos períodos individualmente.

Já o último colocado na fase classificação foi superior aos adversários no primeiro $\left(1^{\circ} \mathrm{P}\right)$ e quarto períodos $\left(4^{\circ} \mathrm{P}\right)$, mas inferior nos demais, o que corrobora a suposição sobre a importância da profundidade do elenco. O segundo período $\left(2^{\circ} \mathrm{P}\right)$ mostrou-se importante para ser o último colocado na fase de classificação, não sendo pior somente do que terminar o terceiro período $\left(1^{\circ}, 2^{\circ}\right.$ e $3^{\circ} \mathrm{P}$ somados $)$ atrás no placar. 
TABELA 04

Frequência e percentual de vezes em que primeiro e último colocado na fase de classificação venceram o período ou soma de períodos e diferença entre eles:

$\begin{array}{cccc}\text { Período } & \begin{array}{c}\text { Primeiro } \\ \text { colocado }\end{array} & \begin{array}{c}\text { Útimo } \\ \text { colocado }\end{array} & \text { Diferença } \\ \mathbf{1}^{\circ} \mathbf{P} & 18(69,2 \%) & 11(44 \%) & 7(25,2 \%) \\ \mathbf{2}^{\circ} \mathbf{P} & 18(69,2 \%) & 5(20 \%) & 13(48,2 \%) \\ \mathbf{3}^{\circ} \mathbf{P} & 19(73,1 \%) & 6(24 \%) & 13(49,1 \%) \\ \mathbf{4}^{\circ} \mathbf{P} & 12(46,2 \%) & 10(40 \%) & 2(6,2 \%) \\ \mathbf{1}^{\circ} \mathbf{e} \mathbf{2}^{\circ} \mathbf{P} \text { somados } & 21(80,8 \%) & 6(24 \%) & 15(56,8 \%) \\ \mathbf{1}^{\circ} \mathbf{2}^{\circ} \mathbf{e} \mathbf{3}^{\circ} \mathbf{P} & 22(84,6 \%) & 5(20 \%) & 17(64,6 \%) \\ \text { somados } & & & \end{array}$

Fonte: dados da pesquisa.

A Tabela 04 deixa claro que o período mais vencido pela equipe primeira colocada na fase de classificação foi o terceiro $\left(3^{\circ} \mathrm{P}\right)$, seguindo de perto pelo primeiro $\left(1^{\circ} \mathrm{P}\right)$ e segundo $\left.2^{\circ} \mathrm{P}\right)$. Ainda que a maior diferença de pontos em relação aos adversários seja no primeiro período $\left(1^{\circ} \mathrm{P}\right)$, a equipe venceu mais vezes o terceiro $\left(3^{\circ}\right.$ $\mathrm{P})$. Porém, mais uma vez, verifica-se que terminar o segundo $\left(1^{\circ} \mathrm{e} 2^{\circ} \mathrm{P}\right.$ somados $)$ e terceiro períodos $\left(1^{\circ}, 2^{\circ} \mathrm{e}\right.$ $3^{\circ} \mathrm{P}$ somados) à frente é mais importante do que vencer cada período isoladamente.

No caso do último colocado, o período mais vezes perdido foi o segundo $\left(2^{\circ} \mathrm{P}\right)$, seguido de perto pelo terceiro $\left(3^{\circ} \mathrm{P}\right)$. Porém, terminar o terceiro $\left(1^{\circ}, 2^{\circ}\right.$ e $3^{\circ} \mathrm{P}$ somados) e o segundo período $\left(1^{\circ}\right.$ e $2^{\circ} \mathrm{P}$ somados $)$ atrás no placar mostraram-se dados mais importantes para ser último colocado na fase de classificação. A diferença entre as equipes na quantidade de vezes que cada uma terminou o terceiro período $\left(1^{\circ}, 2^{\circ}\right.$ e $3^{\circ}$ $P$ somados) à frente do placar ressalta a importância desse indicador para que uma equipe seja primeira ou última colocada na competição. Ferreira e Barreto (2017) identificaram resultado semelhante, enquanto Canan, Mendes e Silva (2015) identificaram que terminar o segundo período à frente $\left(1^{\circ} \mathrm{e} 2^{\circ} \mathrm{P}\right.$ somados) é mais importante do que terminar o terceiro $\left(1^{\circ}, 2^{\circ}\right.$ e $3^{\circ} \mathrm{P}$ somados $)$ à frente.

\section{Indicadores diretos:}

Os indicadores diretos, como já apontado, resumem-se pelas ações mais básicas e quantificáveis do que os jogadores fazem ao longo da partida (De Rose Junior, Tavares \& Gitti, 2004; De Rose Junior, Gaspar \& Assumpção, 2005; Dias Neto, 2007; Csataljay et al., 2009; Malarranha, 2011; Canan, Mendes \& Silva, 2015; Meneses, Gois Junior \& Almeida, 2016; Prochnow et al., 2017). Não levam em conta tomadas de decisão certas ou erradas ou situações específicas do jogo, sendo, por isso, considerados indicadores quantitativos e não qualitativos. Isso não significa que não sejam importantes e que não ofereçam um importante panorama da partida, principalmente se complementados por indicadores indiretos. Ao mesmo tempo, podem ser complementados por outros indicadores diretos, que, embora possam ajudar a ilustrar a partida em números, são mais raramente aferidos, como a quantidades de corta-luzes diretos e indiretos, faltas de ataque sofridas, quantidade de arremessos errados pelo adversário quando sofria marcação individual (defensor à uma distncia de um metro ou menos), entre outros.

Importante salientar que, dentre os dados apresentados pelos indicadores de jogo (box scores) oficiais das partidas do NBB 2018-2019, somente as enterradas não foram consideradas para a presente pesquisa, pois nada mais são do que arremessos de 2 pontos com um caráter plástico. Os demais exemplos de indicadores 
diretos possíveis de serem aferidos não são disponibilizados e possivelmente não são coletados pela LNB. Não se pode perder de vista que a superioridade em alguns indicadores pode ser negativa, pois eles indicam algo ruim feito pela equipe ao longo da partida. Ou seja, há indicadores negativos, que, quanto menos a equipe fizer, melhor, como é caso dos arremessos errados, faltas cometidas e erros (desperdícios de posse de bola).

TABELA 05

Total e média do vencedor e perdedor de cada partida em cada indicador direto e diferença entre eles (o resultado negativo na coluna de diferenças significa que o vencedor perdeu do perdedor naquele indicador):

$\begin{array}{cccc}\text { Indicador } & \text { Vencedor } & \text { Perdedor } & \text { Diferença } \\ \text { direto } & & & \\ \text { 3PT } & 4730(26,4) & 4643(26) & 87(0,5) \\ \text { 3PC } & 1772(9,9) & 1424(8) & 348(1,9) \\ \text { 3PE } & 2958(16,6) & 3219(18) & -261(- \\ \text { 2PT } & 6696(37,4) & 6666(37,2) & 30(0,2) \\ \text { 2PC } & 3652(20,4) & 3277(18,3) & 375(2,1) \\ \text { 2PE } & 3044(17) & 3389(18,9) & -345(- \\ \text { LLT } & 3607(20,1) & 3377(18,9) & 230(1,3) \\ \text { LLC } & 2673(15) & 2431(13,6) & 242(1,4) \\ \text { LLE } & 934(5,2) & 946(5,3) & -12(-0,1) \\ \text { AQT } & 11426(63,8) & 11309(63,2) & 117(0,7) \\ \text { AQC } & 5424(30,3) & 4701(26,3) & 723(4) \\ \text { AT } & 15033(84) & 14686(82) & 347(1,9) \\ \text { AC } & 8097(45,2) & 7132(39,8) & 965(5,4) \\ \text { PQT } & 27582 & 27261 & 321(1,8) \\ \text { PQF } & 12620(70,5) & 10826(60,5) & 1794(10) \\ \text { PT } & 31189 & 30638 & 551(3,1) \\ \text { PF } & 15293(85,4) & 13269(74,1) & 2024(11,3) \\ \text { RD } & 5033(28,1) & 4386(24,5) & 647(3,6) \\ \text { RO } & 1983(11,1) & 1903(10,6) & 80(0,4) \\ \text { RT } & 7016(39,2) & 6289(35,1) & 727(4,1) \\ \text { AS } & 3331(18,6) & 2712(15,2) & 619(3,5) \\ \text { BR } & 1307(7,3) & 1219(6,8) & 88(0,5) \\ \text { TO } & 372(2,1) & 340(1,9) & 32(0,2) \\ \text { FC } & 3624(20,2) & 3835(21,4) & -211(-1,2) \\ \text { FR } & 3666(20,5) & 3487(19,5) & 179(1) \\ \text { ER } & 2416(13,5) & 2578(14,4) & -162(-0,9) \\ & & & \end{array}$

Fonte: dados da pesquisa.

Justamente nos indicadores negativos é que o perdedor de cada partida foi superior ao vencedor. Em todos os demais indicadores, o vencedor foi superior, com destaque para o total de pontos feitos (PF) e total de pontos de quadra feitos (PQF). Em segundo plano, destaque para arremessos de quadra totais (AQT) e convertidos (AQC) e rebotes totais $\mathrm{RT}$ ), este único indicador de destaque não relacionado à pontuação. Resultados semelhantes foram identificados por Csataljay et al. (2009), em estudo ao campeonato europeu, Dias Neto (2007), em relação ao campeonato mundial, Almas (2015) em edição anterior do NBB e Canan, Mendes e Silva (2015) (ver Tabela 06). 
TABELA 06

Frequência e percentual de vezes em que vencedor e perdedor de cada partida venceu no indicador direto, e diferença entre eles:

\begin{tabular}{|c|c|c|c|}
\hline $\begin{array}{l}\text { Indicador } \\
\text { direto }\end{array}$ & Vencedor & Perdedor & Diferença \\
\hline $3 \mathrm{PT}$ & $94(52,5 \%)$ & $77(43 \%)$ & $17(9,5 \%)$ \\
\hline $3 \mathrm{PC}$ & $111(62 \%)$ & $51(28,5 \%)$ & $60(33,5 \%)$ \\
\hline $3 \mathrm{PE}$ & $69(38,6 \%)$ & $103(57,5 \%)$ & $-34(19 \%)$ \\
\hline $2 \mathrm{PT}$ & $92(51,4 \%)$ & $84(46,9 \%)$ & $8(4,5 \%)$ \\
\hline $2 \mathrm{PC}$ & $110(61,5 \%)$ & $49(27,4 \%)$ & $61(34,1 \%)$ \\
\hline $2 \mathrm{PE}$ & $70(39,1 \%)$ & $98(54,8 \%)$ & $\begin{array}{c}-28 \\
(15,6 \%)\end{array}$ \\
\hline LLT & $98(54,8 \%)$ & $71(39,7 \%)$ & $27(15,1 \%)$ \\
\hline LLC & $92(51,4 \%)$ & $73(40,8 \%)$ & $19(10,6 \%)$ \\
\hline LLE & $74(41,3 \%$ & $83(46,4 \%)$ & $-9(5 \%)$ \\
\hline AQT & $94(52,5 \%)$ & $75(41,9 \%)$ & $19(10,6 \%)$ \\
\hline$A Q C$ & $143(79,9 \%)$ & $25(14 \%)$ & $118(65,9 \%)$ \\
\hline AT & $101(56,4 \%)$ & $66(36,9 \%)$ & $35(19,6 \%)$ \\
\hline AC & $152(84,9 \%)$ & $20(11,2 \%)$ & $132(73,7 \%)$ \\
\hline PQT & $96(53,6 \%)$ & $81(45,3 \%)$ & $15(8,4 \%)$ \\
\hline PQF & $146(81,6 \%)$ & $21(11,8 \%)$ & $125(69,8 \%)$ \\
\hline PT & $103(57,5 \%)$ & $74(41,3 \%)$ & $29(16,2 \%)$ \\
\hline $\mathrm{RD}$ & $129(72 \%)$ & $40(22,3 \%)$ & $89(49,7 \%)$ \\
\hline RO & $80(44,7 \%)$ & $84(46,9 \%)$ & $-4(2,2 \%)$ \\
\hline RT & $116(64,8 \%)$ & $56(32,3 \%)$ & $60(33,5 \%)$ \\
\hline AS & $122(68,2 \%)$ & $44(24,6 \%)$ & $78(43,6 \%)$ \\
\hline BR & $92(51,4 \%)$ & $78(43,6 \%)$ & $14(7,8 \%)$ \\
\hline To & $75(41,9 \%)$ & $62(34,6 \%)$ & $13(7,3 \%)$ \\
\hline FC & $64(35,8 \%)$ & $98(54,7 \%)$ & $-34(19 \%)$ \\
\hline FR & $90(50,3 \%)$ & $70(39,1 \%)$ & $20(11,2 \%)$ \\
\hline ER & $72(40,2 \%)$ & $93(52 \%)$ & $\begin{array}{c}-21 \\
(11,7 \%)\end{array}$ \\
\hline
\end{tabular}

Fonte: dados da pesquisa.

Mais uma vez que o vencedor de cada partida foi superior em todos os indicadores positivos de jogo, exceto no caso dos rebotes ofensivos (RO). Contudo, esse indicador não pode ser interpretado isoladamente, pois uma maior quantidade de rebotes ofensivos de uma equipe pode também significar uma maior quantidade de erros de arremesso. As maiores diferenças entre vencedor e perdedor são relativas à pontuação, destacando-se os arremessos (AQC) e pontos de quadra (PQF). São indicadores importantes para vitória em cada partida também, os rebotes defensivos (RD) e as assistências (AS), corroborando o identificado por Almas (2015) e Prochnow etal. (2017) em relação a edições anteriores do NBB (ver Tabela 07). 
TABELA 07:

Total e média do primeiro e último colocado na fase de classificação e de seus respectivos adversários em cada indicador direto, e diferença entre eles

\begin{tabular}{|c|c|c|c|c|c|c|}
\hline $\begin{array}{l}\text { Indicado } \\
\quad \mathbf{r} \\
\text { direto }\end{array}$ & $\begin{array}{l}\text { Primeiro } \\
\text { colocado }\end{array}$ & $\begin{array}{l}\text { Adversário } \\
\text { s do } \\
\text { primeiro } \\
\text { colocado }\end{array}$ & $\begin{array}{c}\text { Diferença } \\
\text { primeiro } \\
\text { colocado e } \\
\text { adversário } \\
\text { s }\end{array}$ & $\begin{array}{l}\text { Ùtimo } \\
\text { colocado }\end{array}$ & $\begin{array}{l}\text { Adversário } \\
\text { s do último } \\
\text { colocado }\end{array}$ & $\begin{array}{c}\text { Diferença } \\
\text { último } \\
\text { colocado e } \\
\text { adversários }\end{array}$ \\
\hline 3PT & $744(28,6)$ & $672(25,8)$ & $72(2,8)$ & $729(29,2)$ & $609(24,4)$ & $120(4,8)$ \\
\hline $3 \mathrm{PC}$ & $279(10,7)$ & $209(8)$ & $70(2,7)$ & $257(10,3)$ & $216(8,6)$ & $41(1,6)$ \\
\hline 3PE & $465(17,9)$ & $463(17,8)$ & $2(0,1)$ & $472(18,9)$ & $393(15,7)$ & $79(3,2)$ \\
\hline 2PT & $870(33,5)$ & $995(38,3)$ & $-125(-4,8)$ & $884(35,4)$ & $1039(41,6)$ & $-155(-6,2)$ \\
\hline $2 \mathrm{PC}$ & $516(19,8)$ & $522(20,1)$ & $-6(-0,2)$ & $420(16,8)$ & $568(22,7)$ & $-148(-5,9)$ \\
\hline 2PE & $354(13,6)$ & $473(18,2)$ & $-119(-4,6)$ & $464(18,6)$ & $471(18,8)$ & $-7(-0,3)$ \\
\hline LLT & $486(18,7)$ & $423(16,3)$ & $63(2,4)$ & $444(17,8)$ & $480(19,2)$ & $-36(-1,4)$ \\
\hline LLC & $389(15)$ & $321(12,3)$ & $68(2,6)$ & $304(12,2)$ & $348(13,9)$ & $-44(-1,8)$ \\
\hline LLE & $97(3,7)$ & $102(3,9)$ & $-5(-0,2)$ & $140(5,6)$ & $132(5,3)$ & $8(0,3)$ \\
\hline$A Q T$ & $1614(62,1)$ & $1667(64,1)$ & $-53(-2)$ & $1613(64,5)$ & $1648(65,9)$ & $-35(-1,4)$ \\
\hline $\mathrm{AQC}$ & $795(30,6)$ & $731(28,1)$ & $64(2,5)$ & $677(27,1)$ & $784(31,4)$ & $-107(-4,3)$ \\
\hline AT & $2100(80,8)$ & $2090(80,4)$ & $10(0,4)$ & $2057(82,3)$ & $2128(85,1)$ & $-71(-2,8)$ \\
\hline AC & $1184(45,5)$ & $1052(40,5)$ & $132(5,1)$ & $981(39,2)$ & $1132(45,3)$ & $-151(-6)$ \\
\hline PQT & $\begin{array}{c}3972 \\
(152,8)\end{array}$ & $\begin{array}{c}4006 \\
(154,1)\end{array}$ & $-34(-1,3)$ & $\begin{array}{c}3955 \\
(158,2)\end{array}$ & $\begin{array}{c}3905 \\
(156,2)\end{array}$ & $50(2)$ \\
\hline PQF & $1869(71,9)$ & $1671(64,3)$ & $198(7,6)$ & $1611(64,4)$ & $1784(71,4)$ & $-173(-6,9)$ \\
\hline PT & $\begin{array}{c}4458 \\
(171,5)\end{array}$ & $\begin{array}{c}4429 \\
(170,3)\end{array}$ & $29(1,1)$ & $4399(176)$ & $\begin{array}{c}4385 \\
(175,4)\end{array}$ & 6) \\
\hline PF & $2258(86,8)$ & $1992(76,6)$ & $266(10,2)$ & $1915(76,6)$ & $2132(85,3)$ & $-217(-8,7)$ \\
\hline $\mathrm{RD}$ & $707(27,2)$ & $632(24,3)$ & $75(2,9)$ & $613(24,5)$ & $726(29)$ & $-113(-4,5)$ \\
\hline RO & $218(8,4)$ & $266(10,2)$ & $-48(-1,8)$ & $257(10,3)$ & $312(12,5)$ & $-55(-2,2)$ \\
\hline RT & $925(35,6)$ & $898(34,5)$ & $27(1)$ & $870(34,8)$ & $1038(41,5)$ & $-168(-6,7)$ \\
\hline AS & $465(17,9)$ & $366(14,1)$ & $99(3,8)$ & $341(13,6)$ & $463(18,5)$ & $-122(-4,9)$ \\
\hline BR & $179(6,9)$ & $160(6,2)$ & $19(0,8)$ & $182(7,3)$ & $174(7)$ & $8(0,3)$ \\
\hline To & $49(1,9)$ & $42(1,6)$ & $7(0,3)$ & $60(2,4)$ & $54(2,2)$ & $6(0,2)$ \\
\hline FC & $472(18,2)$ & $550(21,2)$ & $-78(-3)$ & $509(20,4)$ & $467(18,7)$ & $42(1,7)$ \\
\hline FR & $523(20,1)$ & $456(17,5)$ & $67(2,6)$ & $454(18,2)$ & $495(19,8)$ & $-41(-1,6)$ \\
\hline ER & $312(12)$ & $342(13,2)$ & $-30(-1,2)$ & $352(14,1)$ & $350(14)$ & $2(0,1)$ \\
\hline
\end{tabular}

Fonte: dados da pesquisa.

O primeiro colocado da competição tentou, acertou e errou menos arremessos de 2 pontos (2PT, 2PC, 2PE) que seus adversários. Contudo, a diferença entre os arremessos de 2 pontos certos (2PC) foi bastante menor que de tentados (2PT) e errados (2PE), o que significa que o primeiro colocado da fase de classificação selecionou melhor seus arremessos de 2 pontos, aumentando as condições de acerto. Também tentou menos arremessos (AQT) e pontos de quadra (PQT), errou menos lances livres (LLE), cometeu menos faltas (FC), teve menos desperdícios de bola (ER) e pegou menos rebotes ofensivos (RO). Assim como o vencedor de cada partida, o primeiro colocado na fase de classificação, por errar menos arremessos que os adversários, teve menos oportunidades de conquistar rebotes ofensivos (RO). As assistências (AS) demonstraram-se um importante indicador para primeira colocação na fase de classificação, corroborando o encontrado por Prochnow et al., (2017), além de Dias Neto (2007) e Canan, Mendes e Silva (2015).

A equipe última colocada da fase de classificação arremessou, acertou e errou mais de 3 pontos (3PT, 3PC, $3 \mathrm{PE})$ que seus adversários, arremessou, acertou e errou menos de 2 pontos (2PT, 2PC, 2PE) e arremessou e acertou menos lances livres (LLT, LLC). Exceto nos arremessos errados de 3 pontos (3PE), foi superior ao seu adversário em todos os demais indicadores negativos. A diferença expressiva em rebotes totais (RT), indicador não relacionado à pontuação com maior diferença em desfavor do último colocado, sugere sua importância para que uma equipe não fique nessa posição na fase de classificação (ver Tabela 08). 
TABELA 08

Frequência e percentual de vezes em que primeiro e último colocado na fase de classificação venceu no indicador direto, e diferença entre eles:

\begin{tabular}{|c|c|c|c|}
\hline $\begin{array}{c}\text { Indicador } \\
\text { direto }\end{array}$ & $\begin{array}{l}\text { Primeiro } \\
\text { colocado }\end{array}$ & Ùtimo colocado & Diferença \\
\hline 3PT & $15(57,7 \%)$ & $14(56 \%)$ & $1(7 \%)$ \\
\hline $3 P C$ & $18(69,2 \%)$ & $18(72 \%)$ & $0(-2,8 \%)$ \\
\hline 3PE & $11(42,3 \%)$ & $18(72 \%)$ & $\begin{array}{c}-7(- \\
29,7 \%)\end{array}$ \\
\hline 2PT & $8(30,8 \%)$ & $3(12 \%)$ & $5(18,8 \%)$ \\
\hline $2 \mathrm{PC}$ & $14(53,8 \%)$ & $0(0 \%)$ & $14(53,8 \%)$ \\
\hline 2PE & $5(19,2 \%)$ & $10(40 \%)$ & $\begin{array}{c}-5(- \\
20,8 \%)\end{array}$ \\
\hline LLT & $14(53,8 \%)$ & $6(24 \%)$ & $8(29,8 \%)$ \\
\hline LLC & $13(50 \%)$ & $10(40 \%)$ & $3(10 \%)$ \\
\hline LLE & $9(34,6 \%)$ & $12(48 \%)$ & $\begin{array}{c}-3(- \\
13,4 \%)\end{array}$ \\
\hline $\mathrm{AQT}$ & $10(38,5 \%)$ & $10(40 \%)$ & $0(-1,5 \%)$ \\
\hline $\mathrm{AQC}$ & $13(50 \%)$ & $5(20 \%)$ & $8(30 \%)$ \\
\hline AT & $13(50 \%)$ & $9(36 \%)$ & $4(14 \%)$ \\
\hline $\mathrm{AC}$ & $20(76,9 \%)$ & $3(12 \%)$ & $17(64,9 \%)$ \\
\hline PQT & $10(38,5 \%)$ & $13(52 \%)$ & $-3(-13,5)$ \\
\hline $\mathrm{PQF}$ & $17(65,4 \%)$ & $7(28 \%)$ & $10(37,4 \%)$ \\
\hline PT & $12(46,2 \%)$ & $11(44 \%)$ & $1(2,2 \%)$ \\
\hline RD & $19(73,1 \%)$ & $2(8 \%)$ & $17(65,1 \%)$ \\
\hline Ro & $11(42,3 \%)$ & $8(32 \%)$ & $3(10,2 \%)$ \\
\hline RT & $15(57,7 \%)$ & $5(20 \%)$ & $10(27,7 \%)$ \\
\hline AS & $21(80,8 \%)$ & $4(16 \%)$ & $17(64,8 \%)$ \\
\hline BR & $14(53,8 \%)$ & $11(44 \%)$ & $3(9,8 \%)$ \\
\hline Tо & $13(50 \%)$ & $11(44 \%)$ & $2(6 \%)$ \\
\hline FC & $6(23,1 \%)$ & $13(52 \%)$ & $-7(-28,9 \%)$ \\
\hline FR & $17(65,4 \%)$ & $8(32 \%)$ & $9(33,4 \%)$ \\
\hline ER & $8(30,8 \%)$ & $12(48 \%)$ & $\begin{array}{c}-4(- \\
17,2 \%)\end{array}$ \\
\hline
\end{tabular}

Fonte: dados da pesquisa.

Outra vez a equipe última colocada foi superior nos indicadores negativos. Ao mesmo tempo, foi superior nos pontos de quadra tentados (PQT), o que, apesar de demonstrar algum volume de jogo, indica também que a equipe erra muitos arremessos. Rebotes defensivos (RD), total de arremessos convertidos (AC), assistências (AS) e arremessos de 2 pontos convertidos (2PC) mostram-se indicadores fundamentais para obtenção da primeira colocação na fase de classificação da competição. $O$ último suscita que, apesar da tendência crescente do basquetebol em hipervalorizar os arremessos de 3 pontos, um bom volume nos de 2 pontos ainda mostra-se indispensável para uma campanha positiva.

\section{Indicadores indiretos}

Os indicadores indiretos são obtidos a partir de fórmulas matemáticas que se utilizam dos diretos, somando-se a estes para compreensão dos acontecimentos e padrões de jogo, relativizando alguns números absolutos e contextualizando melhor algumas ações (Kubatko etAl., 2007; Sampaio, Lago \& Drinkwater, 2010; Malarranha, 2011; Enge, 2018; Pivotanalysis, 2019; Nbastuffer, 2020; Araújo, 2020). Porcentagem de arremesso (\%3P, \%2P, \%LL) indica o quanto uma equipe acerta seus arremessos. Eficiência (EF) demonstra quão assertiva é uma equipe em relação ao que é negativa. Assistências por erros (AS/ER) indica se a equipe é cuidadosa com a bola. Bolas recuperadas ou tocos por erros (BR/ER, TO/ER) indica se a equipe tem competência defensiva para compensar os erros ofensivos, impedindo a finalização adversária. Bolas 
recuperadas ou tocos por faltas cometidas $(\mathrm{BR} / \mathrm{FC}, \mathrm{TO} / \mathrm{FC})$ indica se a equipe tem uma defesa agressiva, mas ao mesmo tempo cuidadosa, ou seja, indica se a equipe tem aplicação defensiva qualitativa. Porcentagem de rebotes defensivos (\%RD) diz respeito à competência da equipe para conquista de rebotes defensivos, não apenas levando em conta os conquistados, mas sim o total de possíveis. Posses de bola (PB), indicador de jogo também chamado de pace, indica o ritmo de jogo da equipe. Quanto mais posses, mais arremessos faz e, consequentemente, mais vezes tem a posse de bola. Razão/proporção ofensiva (RAO) e defensiva (RAD) significa quantos pontos, respectivamente, a equipe faz e sofre a cada posse de bola, tendo 100 posses como valor de referência. Por, em sua maioria, tratarem de dados relativos ou percentuais, faz sentido contabilizar apenas as médias.

TABELA 09

Média do vencedor e perdedor de cada partida em cada indicador indireto e diferença entre eles:

$\begin{array}{cccc}\begin{array}{c}\text { Indicador } \\ \text { indireto }\end{array} & \text { Vencedor } & \text { Perdedor } & \text { Diferença } \\ \text { \%3P } & 37,6 & 30,7 & 6,9 \\ \text { \%2P } & 55 & 49,4 & 5,6 \\ \text { \%LL } & 74,6 & 71,4 & 3,2 \\ \text { EF } & 100,6 & 74,6 & 26 \\ \text { AS/ER } & 1,494 & 1,129 & 0,365 \\ \text { BR/ER } & 0,584 & 0,505 & 0,079 \\ \text { BR/FC } & 0,375 & 0,329 & 0,045 \\ \text { TO/ER } & 0,167 & 0,141 & 0,025 \\ \text { TO/FC } & 0,106 & 0,09 & 0,016 \\ \text { \%RD } & 72,8 & 69,3 & 3,5 \\ \text { PB } & 75,1 & 75,3 & -0,1 \\ \text { RAO } & 1,14 & 0,99 & 0,15 \\ \text { RAD } & 0,99 & 1,14 & -0,15\end{array}$

Fonte: dados da pesquisa.

A superioridade em posses de bola (PB) confirma a ideia de que o perdedor de cada partida é menos cuidadoso em relação à seleção de seus arremessos. Corrobora para esse dado, ainda, a superioridade do vencedor de cada partida em percentual de acerto de arremessos (\%3P, \%2P, \%LL), principalmente no caso dos 3 pontos (\%3P). A razão defensiva (RAD) é um indicador negativo, significando, no caso em tela, que o perdedor de cada partida sofre mais pontos a cada 100 posses de bola do vencedor. Uma boa eficiência (EF), ou seja, uma maior competência geral nas ações positivas e maior cuidado com as negativas mostra-se importante para vitória em cada partida, assim como a relação entre assistências e erros (AS/ER). Somadas ao percentual de arremessos (\%3P, \%2P, \%LL), indicam que equipes que cuidam bem da posse de bola e selecionam seus arremessos com calma e qualidade, têm boas condições de vencer cada partida. Canan, Mendes e Silva (2015) encontraram resultados semelhantes em relação à eficiência (EF). Malarranha (2011), estudando o campeonato mundial, identificou superioridade do vencedor e inferioridade do perdedor na razão ofensiva (RAO) e defensiva (RAD), respectivamente. Não foram encontrados estudos que tenham 
comparado vencedores e perdedores de cada partida ou colocações em competições, em relação a outros indicadores indiretos (ver Tabela 10).

TABELA 10

Frequência e percentual de vezes em que vencedor e perdedor de cada partida venceu no indicador indireto, e diferença entre eles:

$\begin{array}{cccc}\begin{array}{c}\text { Indicador } \\ \text { indireto }\end{array} & \text { Vencedor } & \text { Perdedor } & \text { Diferença } \\ \text { \%3P } & 128(71,5 \%) & 50(27,9 \%) & 78(43,6 \%) \\ \text { \%2P } & 124(69,3 \%) & 55(30,7 \%) & 69(38,5 \%) \\ \text { \%LL } & 106(59,2 \%) & 72(40,2 \%) & 34(19 \%) \\ \text { EF } & 166(92,7 \%) & 13(7,3 \%) & 153(85,5 \%) \\ \text { AS/ER } & 128(71,5 \%) & 50(27,9 \%) & 78(43,6 \%) \\ \text { BR/ER } & 103(57,5 \%) & 76(42,5 \%) & 27(15,1 \%) \\ \text { BR/FC } & 104(58,1 \%) & 75(41,9 \%) & 29(16,2 \%) \\ \text { TO/ER } & 103(57,5 \%) & 70(39,1 \%) & 33(18,4 \%) \\ \text { TO/FC } & 96(53,6 \%) & 78(43,6 \%) & 18(10,1 \%) \\ \text { \%RD } & 89(49,7 \%) & 88(49,2 \%) & 1(0,6 \%) \\ \text { PB } & 81(45,3 \%) & 96(53,6 \%) & -15(-8,4 \%) \\ \text { RAO } & 172(96,1 \%) & 7(3,9 \%) & 165(92,2 \%) \\ \text { RAD } & 7(3,9 \%) & 172(96,1 \%) & -165(- \\ & & & 92,2 \%)\end{array}$

Fonte: dados da pesquisa.

Destacam-se como indicadores mais vencidos pelo vencedor de cada partida a razão ofensiva (RAO), seguida da eficiência (EF) e, em menor medida, o percentual de acerto de arremessos de 3 pontos (\%3P) e relação de assistências por erros (AS/ER). Mais uma vez, esses dados indicam melhor controle de bola por parte do vencedor de cada partida, o que também é corroborado pela superioridade do vencedor de cada partida em posses de bola (PB). Canan, Mendes e Silva (2015) encontraram resultados ainda maiores na diferença de vezes em que o vencedor superou o perdedor na eficiência (EF) (ver Tabela 11). 
TABELA 11

Média do primeiro e último colocado na fase de classificação e de seus respectivos adversários em cada indicador indireto, e diferença entre eles:

\begin{tabular}{|c|c|c|c|c|c|c|}
\hline $\begin{array}{l}\text { Indicador } \\
\text { indireto }\end{array}$ & $\begin{array}{l}\text { Primeiro } \\
\text { colocado }\end{array}$ & $\begin{array}{c}\text { Adversários } \\
\text { do primeiro } \\
\text { colocado }\end{array}$ & $\begin{array}{c}\text { Diferença } \\
\text { primeiro } \\
\text { colocado e } \\
\text { adversários }\end{array}$ & $\begin{array}{c}\text { Último } \\
\text { colocado }\end{array}$ & $\begin{array}{c}\text { Adversários } \\
\text { do último } \\
\text { colocado }\end{array}$ & $\begin{array}{c}\text { Diferença } \\
\text { último } \\
\text { colocado e } \\
\text { adversários }\end{array}$ \\
\hline$\% 3 \mathrm{P}$ & 37,5 & 31,5 & 6 & 35 & 35,7 & $-0,7$ \\
\hline$\% 2 \mathrm{P}$ & 59,7 & 52,8 & 6,9 & 47,4 & 54,8 & $-7,4$ \\
\hline$\% \mathrm{LL}$ & 80,1 & 74,1 & 5,9 & 69,5 & 72,7 & $-3,2$ \\
\hline EF & 103,8 & 76,3 & 27,5 & 75,4 & 101,7 & $-26,3$ \\
\hline AS/ER & 1,555 & 1,206 & 0,349 & 1,021 & 1,424 & $-0,402$ \\
\hline BR/ER & 0,603 & 0,527 & 0,076 & 0,535 & 0,516 & 0,019 \\
\hline $\mathrm{BR} / \mathrm{FC}$ & 0,391 & 0,3 & 0,091 & 0,372 & 0,394 & $-0,021$ \\
\hline $\mathrm{TO} / \mathrm{ER}$ & 0,172 & 0,123 & 0,049 & 0,189 & 0,171 & 0,017 \\
\hline $\mathrm{TO} / \mathrm{FC}$ & 0,106 & 0,077 & 0,029 & 0,118 & 0,119 & $-0,001$ \\
\hline$\% \mathrm{RD}$ & 73,2 & 74,3 & $-1,1$ & 67 & 74,1 & $-7,2$ \\
\hline PB & 73,9 & 74,2 & $-0,3$ & 76,1 & 75,9 & 0,2 \\
\hline RAO & 1,18 & 1,03 & 0,14 & 1 & 1,12 & $-0,18$ \\
\hline RAD & 1,03 & 1,18 & $-0,14$ & 1,12 & 1 & 0,18 \\
\hline
\end{tabular}

Fonte: dados da pesquisa.

Os indicadores de percentual de acerto de arremesso (\%3P, \%2P, \%LL), eficiência (EF) e assistências por erros (AS/ER) também destacam-se para primeira colocação na fase de classificação da competição. No caso do último colocado na fase de classificação, além dos dados relativos a percentual de arremessos (\%3P, \%2P, \%LL), chama atenção a quantidade de erros para cada assistência (AS/ER) e o percentual de rebotes defensivos (\%RD). Ou seja, a equipe não cuida bem da bola e permite muitos rebotes ofensivos (segundas chances de arremesso) aos adversários. 
TABELA 12

Frequência e percentual de vezes em que primeiro e último colocado na fase de classificação venceu no indicador indireto, e diferença entre eles:

$\begin{array}{cccc}\begin{array}{c}\text { Indicador } \\ \text { indireto }\end{array} & \begin{array}{c}\text { Primeiro } \\ \text { colocado }\end{array} & \text { Último colocado } & \text { Diferença } \\ \text { \%3P } & 20(76,9 \%) & 8(32 \%) & 12(44,9 \%) \\ \text { \%2P } & 18(69,2 \%) & 4(16 \%) & 14(53,2 \%) \\ \text { \%LL } & 17(65,4 \%) & 8(32 \%) & 9(33,4 \%) \\ \text { EF } & 22(84,6 \%) & 4(16 \%) & 18(68,6 \%) \\ \text { AS/ER } & 20(76,9 \%) & 1(4 \%) & 19(72,9 \%) \\ \text { BR/ER } & 15(57,7 \%) & 12(48 \%) & 4(13,7 \%) \\ \text { BR/FC } & 18(69,2 \%) & 10(40 \%) & 8(29,2 \%) \\ \text { TO/ER } & 18(69,2 \%) & 11(44 \%) & 7(25,2 \%) \\ \text { TO/FC } & 15(57,7 \%) & 12(48 \%) & 3(9,7 \%) \\ \text { \%RD } & 12(46,2 \%) & 5(20 \%) & 7(26,3 \%) \\ \text { PB } & 13(50 \%) & 16(64 \%) & -3(-14 \%) \\ \text { RAO } & 23(88,5 \%) & 3(12 \%) & 20(76,5 \%) \\ \text { RAD } & 3(11,5 \%) & 22(88 \%) & -19(- \\ & & & 76,5 \%)\end{array}$

Fonte: dados da pesquisa.

A razão ofensiva (RAO) mostra-se como indicador com maior diferença entre primeiro e último colocados na fase de classificação da competição. Importante apontar que as 23 vezes em que o primeiro colocado na fase de classificação foi superior aos seus adversários foram justamente nas vitórias de equipe (esse dado não consta na Tabela 12, mas foi também coletado). Relação entre assistências e erros (AS/ER) e eficiência (EF), novamente apresentam-se como indicadores que indicam alta possibilidade de primeira colocação na fase de classificação da competição. Canan, Mendes e Silva (2015) identificaram que o primeiro colocado na fase de classificação foi superior em eficiência (EF) aos seus adversários em 100\% dos casos.

\section{4 fatores ( 4 factors):}

Os 4 fatores são também indicadores indiretos, mas vêm sistematicamente sendo agrupados como indicadores à parte, considerados decisivos para uma equipe ser vitoriosa (Kubatko etel., 2007; Malarranha, 2011; Enge, 2018; Pivotanalysis, 2019; Nbastuffer, 2020).

Porcentagem efetiva de arremessos de quadra (\%EAQ) não apenas relaciona arremessos tentados e convertidos, mais também atribui um peso um pouco maior aos arremessos de 3 pontos, demonstrando a qualidade de uma equipe em relação à escolha e eficácia de suas finalizações. Porcentagem de rebotes ofensivos (\%RO) diz respeito à competência da equipe para conquista de rebotes de rebotes ofensivos, não apenas levando em conta os conquistados, mas sim o total de possíveis. A razão de lances livres tentados (RALLT) visa identificar quantos lances livres a equipe cobra em relação à quantidade de arremessos de quadra. Leva em consideração que a porcentagem de acerto de lances livres é costumeiramente maior do que a porcentagem 
de acerto de arremessos de quadra, de forma que, quanto mais lances livres a equipe cobra, melhor. A razão de erros (RAER) diz respeito à relação entre erros e posses de bola da equipe. Quanto maior, pior, ou seja, quanto maior a proporção, significa que mais a equipe desperdiça a bola sem arremessá-la.

TABELA 13

Média do vencedor e perdedor de cada partida em cada fator e diferença entre eles:

$\begin{array}{cccc}\text { Fator } & \text { Vencedor } & \text { Perdedor } & \text { Diferença } \\ \text { \%EAQ } & 55,5 & 30,7 & 7,5 \\ \text { \%RO } & 30,7 & 27,2 & 3,5 \\ \text { RALLT } & 0,321 & 0,303 & 0,018 \\ \text { RAER } & 0,157 & 0,168 & -0,011\end{array}$

Fonte: dados da pesquisa.

Como esperado, o vencedor de cada partida foi superior em todos os fatores, exceto na razão de erros (RAER). Contudo, o único indicador que apresentou uma diferença substancialmente superior à maioria dos demais indicadores diretos e indiretos, foi a porcentagem efetiva de arremessos de quadra (\%EAQ), o que coincide com os altos valores encontrados nas Tabelas 05 e 09 em relação a arremessos convertidos (AC), pontos feitos (PF) e percentuais de acerto em geral (\%3P, \%2P, \%LL). Esses dados somados deixam bastante clara a importância da seleção e percentual de acerto dos arremessos, muito mais do que a própria quantidade de arremessos realizados.

O percentual de rebotes ofensivos (\%RO) também mostra-se um fator importante, principalmente se for levado em conta que a diferença na média de rebotes ofensivos $(\mathrm{RO})$ do vencedor e perdedor de cada partida (Tabela 05) foi praticamente nula. Ou seja, o perdedor de cada partida, ao longo da fase de classificação, conquistou praticamente a mesma quantidade de rebotes ofensivos que o vencedor, mas percentualmente em relação aos rebotes ofensivos possíveis, o vencedor foi muito mais efetivo. Em outras palavras, o vencedor de cada partida é mais competente em conquistar rebotes ofensivos do que o perdedor, sendo este um fator importante para vitória. Malarranha (2011) encontrou resultados semelhantes em relação aos percentuais efetivos de arremessos de quadra (\%EAQ) e rebotes ofensivos (\%RO).

TABELA 14

Frequência e percentual de vezes em que vencedor e perdedor de cada partida venceu no fator, e diferença entre eles:

$\begin{array}{cccc}\text { Fator } & \text { Vencedor } & \text { Perdedor } & \text { Diferença } \\ \text { \%EAQ } & 150(83,8 \%) & 29(16,2 \%) & 121(67,6 \%) \\ \text { \%RO } & 98(54,7 \%) & 78(43,6 \%) & 20(11,2 \%) \\ \text { RALLT } & 97(54,2 \%) & 82(45,8 \%) & 15(8,4 \%) \\ \text { RAER } & 78(43,6 \%) & 101(56,4 \%) & -23 \\ & & & (12,9 \%)\end{array}$

Fonte: dados da pesquisa.

Assim como no caso anterior, destaque para o percentual efetivo de arremessos de quadra (\%EAQ). Contudo, diferentemente do identificado nas médias (Tabela 13), a diferença na razão de erros (RAER) mostrou-se superior à de porcentagem de rebotes ofensivos (\%RO) e razão de lances livres tentados (RALLT). A diferença nos resultados entre as Tabelas 13 e 14 indica que, em termos relativos, o vencedor 
errou muito em algumas partidas e/ou o perdedor errou pouco em algumas partidas, mas, no geral, vencedor errou menos em muito mais partidas e perdedor errou mais em muitos mais partidas (ver Tabela 15).

Tabela 15: Média do primeiro e último colocado na fase de classificação e de seus respectivos adversários em cada fator, e diferença entre eles:

TABELA 15

Média do primeiro e último colocado na fase de classificação e de seus respectivos adversários em cada fator, e diferença entre eles:

$\begin{array}{ccccccc}\text { Fator } & \begin{array}{c}\text { Primeiro } \\ \text { colocado }\end{array} & \begin{array}{c}\text { Adversários } \\ \text { do primeiro } \\ \text { colocado }\end{array} & \begin{array}{c}\text { Diferença } \\ \text { primeiro } \\ \text { colocado e } \\ \text { adversários }\end{array} & \begin{array}{c}\text { Úlimo } \\ \text { colocado }\end{array} & \begin{array}{c}\text { Adversários } \\ \text { do último } \\ \text { colocado }\end{array} & \begin{array}{c}\text { Diferença } \\ \text { último } \\ \text { colocado e } \\ \text { adversários }\end{array} \\ \text { \%EAQ } & 58,1 & 50,5 & 7,7 & 50,1 & 54,3 & -4,2 \\ \text { \%RO } & 25,7 & 26,8 & -1,1 & 25,9 & 33 & -7,2 \\ \text { RALLT } & 0,306 & 0,257 & 0,049 & 0,282 & 0,295 & -0,012 \\ \text { RAER } & 0,146 & 0,156 & -0,01 & 0,163 & 0,158 & 0,005\end{array}$

Fonte: dados da pesquisa.

Os quatro fatores são fidedignos, estando relacionados à primeira ou última colocação na fase de classificação. Destaque positivo para a porcentagem efetiva de arremessos de quadra (\%EAQ) no caso do vencedor e destaque negativo no percentual de rebotes ofensivos (\%RO) no caso do primeiro e do último colocados.

TABELA 16

Frequência e percentual de vezes em que primeiro e último colocados na fase de classificação venceu no fator, e diferença entre eles:

$\begin{array}{cccc}\text { Fator } & \begin{array}{c}\text { Primeiro } \\ \text { colocado }\end{array} & \text { Último colocado } & \text { Diferença } \\ \text { \%EAQ } & 22(84,6 \%) & 7(28 \%) & 15(56,6 \%) \\ \text { \%RO } & 12(46,2 \%) & 6(24 \%) & 6(22,2 \%) \\ \text { RALLT } & 14(53,8 \%) & 9(36 \%) & 5(17,8 \%) \\ \text { RAER } & 10(38,5 \%) & 12(48 \%) & -2(-9,5 \%)\end{array}$

Fonte: dados da pesquisa.

O que chama atenção na Tabela 16 é que, em termos relativos, o primeiro colocado errou pouco menos (RAER) que o último colocado. Anda que a superioridade ou inferioridade nesse indicador confirme, respectivamente primeira ou última colocação na fase de classificação, ele se mostrou pouco importante se comparado aos demais fatores, cujas diferenças foram superiores, com destaque, novamente, para o percentual efetivo de arremessos de quadra (\%EAQ). O fato do primeiro colocado na fase de classificação perder de seus adversários na média e na quantidade de vezes em que foi superior em percentual de rebotes ofensivos (\%RO) demonstra que esse fator, embora importante para vitória em cada partida, não é preponderante para primeira colocação na fase de classificação. 


\section{CONSIDERAÇÕES FINAIS}

A temporada 2018-2019 do NBB, corroborando a literatura de maneira geral, além de indicar uma comum superioridade da equipe vencedora de cada partida ou primeira colocada na fase de classificação em todos ou na maioria dos indicadores positivos, ressalta a importância do cuidado com a posse de bola e melhor seleção de arremessos, consequentemente aumentando sua eficácia, ou seja, a porcentagem de acertos. Os rebotes, em termos absolutos e percentuais também mostraram-se como importantes indicadores de jogo para obtenção da vitória em cada partida, mas menos para primeira colocação na fase de classificação.

A grupo chamado de quatro fatores mostrou-se fidedigno, sendo, em praticamente todas as análises (exceto no caso da média no percentual de rebotes ofensivos do primeiro colocado na fase de classificação) associado à vitória (porcentagem efetiva de arremessos de quadra, porcentagem de rebotes ofensivos e razão de lances livres tentados) ou derrota (razão de erros). Contudo, além da exceção identificada em relação ao percentual de rebotes ofensivos, apenas o percentual efetivo de arremessos de quadra apresentou uma diferença expressiva entre vencedor e perdedor de cada partida ou primeiro e último colocado na fase de classificação, corroborando o que já havia sido identificado em relação aos percentuais de acertos e quantidade de pontos em geral.

Pesquisas que busquem identificar novos indicadores e/ou comparem fase de classificação e fase eliminatória (playoffs) e/ou que teçam uma análise estatística mais qualitativa sobre os resultados podem acrescentar ao conhecimento sobre o tema.

\section{REFERÊNCIAS}

Almas, S. P. (2015). Análise das estatísticas relacionadas ao jogo que discriminam as equipes vencedoras das perdedoras no basquetebol profissional brasileiro. Revista Brasileira De Educação Física E Esporte, 29(4), 551-558. DOI: h ttps://doi.org/10.1590/1807-55092015000400551.

Araújo, L. (2020). Como entender as estatísticas avançadas? Canal Triple Double. Disponível em: https://tripledoubl e.com.br/como-entender-as-estatisticas-avancadas/. Acesso em 22 out. 2020.

Canan, F., Mendes, J. C., \& Silva, R. V. da. (2015). Análise estatística no basquetebol de base: perfil do Campeonato Paranaense de Basquetebol masculino Sub-17. Revista Brasileira De Educação Física E Esporte, 29(2), 289-302. DOI: https://doi.org/10.1590/1807-55092015000200289.

Carneiro, F. F. B., Souza, D. R. de \& Costa, F. R. da C. (2015). Contribuições do uso da estatística para a formação de equipes de basquetebol. Coleção Pesquisa em Educação Física, 14(3), 31-40. Disponível em: https://fontouraedi tora.com.br/periodico/home/viewArticle/1186. Acesso em 18 out. 2020.

Carvalho, F., Janeira, M. A. \& Brandão, E. (2006). O poder discriminatório dos indicadores técnico-táticos na performance em basquetebol. In: TAVARES, F. (Ed.). Estudos 6: actas do II Seminário Estudos Universitários em Basquetebol. Porto: FADEUP, 124-32.

Csataljay, G., O’Donoghue, P., Hughes, M. \& Dancs, H. (2009). Performance indicators that distinguish winning and losing teams in basketball. International Journal of Performance Analysis in Sport, 9(1), 60-66. DOI: https://do i.org/10.1080/24748668.2009.11868464.

De Rose Junior, D., Tavares, A. C., \& Gitti, V. (2004). Perfil técnico de jogadores brasileiros de basquetebol: relação entre os indicadores de jogo e posições específicas. Revista Brasileira De Educação Física E Esporte, 18(4), 377-384. DOI: https://doi.org/10.1590/S1807-55092004000400006.

De Rose Junior, D., Gaspar, A. B. \& Assumpção, R. M. (2005). Análise estatística do jogo. In: De Rose Junior, D., Tricoli, V. (Org.). Basquetebol: uma visão integrada entre ciência e prática. Barueri: Manole, 123-43.

De Rose Junior, D. D., \& Lamas, L. (2006). Análise de jogo no basquetebol: perfil ofensivo da Seleção Brasileira Masculina. Revista Brasileira De Educação Física E Esporte, 20(3), 165-173. DOI: https://doi.org/10.1590/S1 807-55092006000300002. 
De Rose Junior, D. \& Silva, S., T. A. F. (2011). As modalidades esportivas coletivas (MEC): história e caracterização. In: De Rose Junior, D. (Org.). Modalidades esportivas coletivas. Rio de Janeiro: Guanabara Koogan, 1-14.

Den Hartigh, R. J. R., Niessen, A. S. M., Frencken, W. G. P. \& Meijer, R. R. (2018). Selection procedures in sports: Improving predictions of athletes' future performance. European Journal of Sport Science, 1(8), 1191-1198. DOI: https://doi.org/10.1080/17461391.2018.1480662.

Dias Neto, J. M. (2006). A importância dos indicadores estatísticos para obtenção da vitória no Campeonato Mundial de Basquetebol adulto masculino. Fitness \& Performance Journal, 6(1), 57-61. DOI: https://10.3900/fpj.6.1.5 7.p.

Enge, R. (2018). Os "four factors", a importância de cada um e como são calculados. Layup: informação de bandeja sobre a NBA. Disponível em: https://layup.com.br/os-four-factors-a-importancia-de-cada-um-e-como-sao-calculado s/ Acesso em 22 out. 2020.

Ferreira, A. P (2006). Do conceito de momentum ao estudo dos momentos críticos do jogo de basquetebol. In: Tavares, F. (Ed.). Estudos 6: Actas do II Seminário Estudos Universitários em Basquetebol. Porto: FADEUP, 43-56.

Ferreira, A. P. \& Barreto, H. Alternâncias do resultado e relação vantagem-vitória: uma visita ao momentum do jogo de basquetebol. In: Tavares, F., Graça, A., Garganta, J., \& Mesquita, I. (Ed.). Olhares e contextos da performance nos jogos desportivos. Porto: FADEUP, 2008. p.180-6.

Kubatko, J., Oliver, D., Pelton, K. \& Rosenbaum, D. (2007). A starting point for analyzing basketball statistics.Journal of Quantitative Analysis in Sports, 3(1), 2-24. DOI: https://doi.org/10.2202/1559-0410.1070.

Larkin, P. \& O'Connor, D. (2017). Talent identification and recruitment in youth soccer: recruiter's perceptions of the key attributes for player recruitment. PLOS ONE, 12(4), 1-15. DOI: https://doi.org/10.1371/journal.po ne.0175716.

Lewis, M. M. (2017). Moneyball: The art of winning an unfair game. New York: WW Norton.

Malarranha, J. M. C. (2011). Modelação dinâmica da performance em basquetebol. Dissertação (Metrado em Treino Desportivo). Universidade de Évora, Évora.

Meneses, L. R., Gois Junior, L. E. M. \& Almeida, M. B. de. (2016). Análise do desempenho do basquetebol brasileiro ao longo de três temporadas do Novo Basquete Brasil. Revista Brasileira de Ciências do Esporte, 38(1), 93-100. DOI: https://doi.org/10.1016/j.rbce.2015.12.002.

NBASTUFFER (2020). Four factors. NABStuffer. Disponível em https://www.nbastuffer.com. Acesso em 22 out. 2020.

PIVOTNALYSIS (2019). Introduction to four factors. Pivotanalysis.com. Disponível em: https://www.pivotanalysis. com/post/what-are-four-factors-basketbal. Acesso em 22 out. 2020.

Prochnow, RA, Reale, VMC, Santos, YYS, Monezi, LA, \& Mercadante, LA (2017). Análise de indicadores técnicos que discriminam times vencedores e perdedores no novo Basquete Brasil. SPORT TK-EuroAmerican Journal of Sports Sciences, 6 (1), 207-212. DOI: https://doi.org/10.6018/293701.

Sampaio, J., Lago, C. \& Drinkwater, E. (2010). Explanations for the United States of America's dominance in basketball at the Beijing Olympic Games (2008). Journal of Sports Sciences, 28(2), 147-152. DOI: https://doi .org/10.1080/02640410903380486.

Tavares, F. (2011). Analisar o jogo nos esportes coletivos para melhorar a performance: uma necessidade para o processo de treino. In: De Rose Junior, D. (Org.). Modalidades esportivas coletivas. Rio de Janeiro: Guanabara Koogan, 60-66.

\section{Notas}

1 A temporada 2019-2020 não foi finalizada em razão da pandemia covid-19. 